03

\title{
Наножидкости для энергетики: механизм влияния диспергентов на тепловые параметры и кризисные явления при кипении
}

\author{
(C) В.Н. Морару, Б.И. Бондаренко, С.В. Сидоренко, Д.В. Комыш \\ Институт газа НАН Украины, \\ 03113 Киев, Украина \\ e-mail: vasily.moraru@gmail.com
}

Поступило в Редакцию 31 мая 2019 г.

В окончательной редакции 31 мая 2019 г.

Принято к публикации 15 сентября 2019 г.

Изучено влияние диспергентов органической (СТАВ) и неорганической природы (пирофосфат и силикат натрия) на величину критического теплового потока и коэффициента теплоотдачи при кипении различных водных наножидкостей в условиях свободной конвекции. Установлено, что добавки ионных диспергентов к алюмосиликатным наножидкостям, повышая их агрегативную и седиментационную устойчивость, как правило, ухудшают тепловые параметры при кипении, вызывая внезапный предкризисный пережог нагревателя в установке, питаемой постоянным током. Раскрыт механизм явления. Показано, что добавки диспергентов и поверхностно-активных веществ к углеродсодержащим наножидкостям с высокой теплопроводностью, улучшая их устойчивость, в то же время повышают коэффициент теплоотдачи при кипении, а также вызывают докризисный пережог нагревателя в случае нагрева постоянным током. Проанализировано влияние диспергентов на кризисные явления при кипении воды и наножидкостей, и выяснены причины внезапного докризисного пережога нагревателя. Предложено несколько механизмов для интерпретации наблюдаемых эффектов. Обоснована целесообразность использования переменного тока нагрева и неионных непенящихся поверхностно-активных веществ и диспергентов для избегания раннего наступления кризиса кипения с целью достижения более высоких значений критического теплового потока и коэффициента теплоотдачи при кипении наножидкостей.

Ключевые слова: наножидкости, кипение, добавки диспергентов, ПАВ, теплоотдача.

DOI: $10.21883 /$ JTF.2020.02.48806.221-19

\section{Введение}

Интенсификация процессов теплообмена - одна из важнейших проблем современной промышленности и энергетики. Один из путей интенсификации теплопереноса - это широкое использование процессов кипения и наножидкостей (НЖ) в качестве теплоносителей, способных работать при высоких удельных тепловых потоках [1].

Многочисленными исследованиями по кипению НЖ, обобщенными в [1-4], показано, что эффект повышения (прирост) тепловых свойств НЖ по сравнению с базовой жидкостью (водой) является функцией концентрации, размера и формы наночастиц (НЧ), а также их химической природы. При этом большинство авторов, как правило, пренебрегают влиянием диспергента (стабилизатора), играющего важнейшую роль в получении и применении НЖ. Этим, в частности, объясняется разброс в результатах различных исследователей, полученных на одних и тех же объектах.

Поскольку механизм влияния диспергентов (и стабилизаторов) на тепловые параметры НЖ, особенно при их кипении, недостаточно понятен, во многих исследованиях избегают их применений. А, как известно, одно из главных технических требований, предъявляемых к НЖ, - их надежная стабилизация. Благодаря разви- тию нанотехнологий в настоящее время иностранными фирмами выпускается широкая гамма микро- и нанопорошков, при изготовлении которых практически всегда используются поверхностно-активные вещества (ПАВ), диспергенты и стабилизаторы различной химической природы и строения. Как правило, названия и остаточная концентрация последних в готовых нанопорошках или в жидких наноконцентратах, поступивших в продажу, часто засекречены и не всегда указываются фирмами на упаковке или в сертификатах качества. По этой причине в подавляющем большинстве работ авторы считают, что они работают с чистыми препаратами, испытывая затем определенные трудности при интерпретации полученных результатов.

Дело в том, что даже очень малые добавки диспергентов и стабилизаторов способны резко изменить не только свойства базовой жидкости $(\mathrm{pH}$, поверхностное натяжение $(\sigma)$, удельную электропроводность $(K))$, но и свойства самих частиц и поверхности теплообмена (химическую природу, заряд, гидрофильность, смачиваемость). Это неминуемо сказывается на тепловых свойствах НЖ, механизм изменения которых остается пока невыясненным.

Прежде всего, следует подчеркнуть, что характер влияния того или иного диспергента на теплопередающие характеристики НЖ принципиально различен при одно- 
фазовом и двухфазовом теплообмене, сопровождаемом фазовым переходом, т. е. кипением теплоносителя. Очевидно, это связано с различным вкладом двух основных способов передачи тепла - теплопроводности и конвекции - в этих случаях. Так, в подавляющем большинстве работ по исследованию влияния наночастиц на теплопроводность НЖ в интервале температур $10-50^{\circ} \mathrm{C}$ [5-8] сообщается о том, что добавки диспергентов и стабилизаторов, способствуя коллоидной устойчивости и равномерному распределению твердой фазы по объему, повышают теплопроводность дисперсии. Например, в работе [5] установлен параллелизм в повышении стабильности и теплопроводности наножидкостей $\mathrm{Al}_{2} \mathrm{O}_{3}-\mathrm{H}_{2} \mathrm{O}$, которые в значительной степени зависят от $\mathrm{pH}$ и концентрации диспергента - додецилбензосульфоната натрия (DBS). Авторами показано, что оптимальным значениям $\mathrm{pH}$ и концентрации DBS отвечают наилучшая устойчивость и максимальная теплопроводность НЖ.

Напротив, почти во всех работах, посвященных теплообмену при кипении НЖ [4,9-18], в процессе которого главную роль играют топологические и химические свойства поверхности нагрева и конвекция, установлено, что добавки диспергентов и стабилизаторов существенно ухудшают параметры теплопередачи - удельный тепловой поток (УТП), критический тепловой поток (КТП) и коэффициент теплоотдачи (КТО).

По мере накопления экспериментальных данных выяснилось, что влияние добавок диспергентов на тепловые параметры при кипении наножидкостей не столь однозначно, как показалось вначале [9]. Позднее мы [10,11] пришли к выводу о том, что в зависимости от концентрации диспергента, кристаллохимической структуры и морфологии наночастиц, а также от рода применяемого электрического тока нагрева, это влияние может быть как положительным, так и отрицательным. По этому вопросу в литературе нет удовлетворительного толкования и единого мнения исследователей [4].

Так, автор работы [12], рассматривая влияние диспергента на теплообмен при кипении фторсодержащих НЖ, отмечает, что введение небольших концентраций ПАВ оказывает вредное влияние на теплопередачу при пузырьковом кипении и слегка понижает КТП.

Авторы статей $[13,14]$ приводят ряд примеров по кипению НЖ, когда наличие диспергента понижает величины КТП и коэффициента теплоотдачи. Зачастую многие исследователи избегают применений диспергента, не подозревая, что он уже присутствует почти во всех случаях. На это указывает систематичный внезапный предкризисный пережог нагревателя, а также форма полученных ими кривых кипения без режима пленочного кипения.

В недавнем обзоре [15] также рассматривается влияние добавок в наножидкости на КТП и коэффициент теплопередачи при пузырьковом кипении. Авторами показано, что поверхностно-активные вещества усиливают зародышевое кипение, но величина усиления зависит от природы аддитива. Кроме того, установлено, что добавки иногда повышают КТП, но могут оказывать негативное влияние на коэффициент теплопередачи при пузырьковом кипении.

Кумар с сотрудниками [16-18] показали, что ионные добавки могут существенно искажать процессы пузырькового кипения и КТП в НЖ, влияя на их стабильность и взаимодействие частиц вблизи нагретой поверхности. Их экспериментальные результаты показали, что, когда значения $\xi$-потенциала НЖ контролируются такими ионными добавками, как $\mathrm{HCl}$ и $\mathrm{NaOH}$, тепловые характеристики НЖ могут быть дополнительно повышены. Однако эти добавки в отличие от обычных диспергентов влияют только на заряд частиц, не затрагивая поверхность нагрева.

С другой стороны, авторы [19] провели эксперименты по определению КТП с НЖ на основе медных наночастиц $(\mathrm{Cu})$, стабилизированных анионным ПАВ лаурилсульфатом натрия (SDS) - и без него. В то время как прирост КТП при кипении НЖ без ПАВ составляло около 50\%, КТП НЖ, стабилизированной SDS, сильно уменьшался, по-видимому, из-за снижения поверхностного натяжения. В заключении авторы отмечают, что влияние ионных добавок и полимерных ПАВ на величину КТП при кипении НЖ может быть существенным, но наше нынешнее понимание эффекта очень ограничено, для чего необходимы дополнительные исследования. Это справедливо отметил Kim Н. в своем обстоятельном обзоре [4]. Введение ионной добавки для управления электростатическим состоянием раствора является одним из самых простых методов улучшения коллоидной стабильности наночастиц в наножидкостях. Однако оно может серьезно изменить характерные структуры отложений наночастиц на поверхности нагревателя, в результате чего происходит искажение пузырькового кипения и снижение КТП [4].

Итак, в литературе нет систематических исследований по влиянию различных химических добавок на КТП и КТО при кипении водных НЖ, что значительно затрудняет разработку эффективных теплоносителей для энергетики.

Целью настоящей работы является выяснение механизма влияния добавок диспергентов и стабилизаторов на характер кривых кипения и величины параметров теплопередачи при кипении нанофлюидов в условиях свободной конвекции.

\section{1. Объекты и методы исследования}

Объектами исследования служили дистиллированная вода (ДВ) и 0.30-0.65\%-ные водные нанодисперсии природной генетической смеси алюмосиликатов - аттапульгита и монтмориллонита (A1Si-7) с частицами игольчато-образной и чешуйчатой форм (Украина) [20,21]. Нанофлюиды получали путем кратковременного (5 min) ультразвукового диспергирования на 
Физико-химические характеристики и значения тепловых параметров $\left(q_{\mathrm{cr}}\right.$ и $\left.\alpha_{\max }\right)$ воды и водных нанофлюидов при кипении в установке постоянного тока

\begin{tabular}{l|c|c|c|c|c|c|c|c}
\hline \multicolumn{1}{c|}{$\begin{array}{c}\text { Исследуемая } \\
\text { жидкость }\end{array}$} & $\begin{array}{c}d, \\
\mathrm{~nm}\end{array}$ & $\begin{array}{c}C_{\mathrm{H},} \\
\text { mass.\% }\end{array}$ & $\begin{array}{c}\sigma, \\
\mathrm{mN} / \mathrm{m}\end{array}$ & $\begin{array}{c}\xi, \\
\mathrm{mV}\end{array}$ & $\mathrm{pH}$ & $\begin{array}{c}K, \\
\mu \mathrm{S} / \mathrm{cm}^{2}\end{array}$ & $\begin{array}{c}q_{\mathrm{cr}} \\
\mathrm{MW} / \mathrm{m}^{2}\end{array}$ & $\begin{array}{c}\alpha_{\mathrm{max}}, \\
\mathrm{W} / \mathrm{m}^{2} \cdot \mathrm{K}\end{array}$ \\
\hline Дистиллированная вода (ДВ) & - & 0 & 72.8 & - & 6.0 & 001 & 1.20 & 25000 \\
AlSi-7 исходная + ДВ & $100-350$ & 0.5 & 72.6 & -20.2 & 5.5 & 024 & 3.70 & 38500 \\
$\mathrm{AlSi}-7+0.05 \%$ ПФН & $50-180$ & 0.5 & 71.7 & -57.0 & 7.0 & 1045 & 1.40 & 27000 \\
УНТ + 0.0365\% ЦТАБ & $179-850$ & 0.1 & 38.4 & +50.2 & 5.9 & 068 & 0.95 & 42000 \\
СА 1/0 исходная + ДБ & $100-500$ & 0.5 & 71.5 & -30.5 & 6.0 & 004 & 1.30 & 37000 \\
СА 1/0 + 0.005\% $\mathrm{Na}_{2} \mathrm{SiO}_{3}$ & $50-250$ & 0.5 & 70.7 & -54.0 & 10.0 & 320 & 1.35 & 45000
\end{tabular}

Примечание $: d-$ средний размер частиц, $C_{\mathrm{H}}-$ концентрация частиц, $\sigma-$ поверхностное натяжение при $20^{\circ} \mathrm{C}, \xi-$ электрокинетический потенциал, $K-$ удельная электропроводность, $q_{\mathrm{cr}}-$ критический тепловой поток пережога и $\alpha_{\max }-$ максимальный коэффициент теплоотдачи.

установке УЗДН-2Т предварительно очищенного образца $\mathrm{AlSi}-7$ в ДВ и в растворах различной концентрации неорганического диспергента - пирофосфата натрия $\mathrm{Na}_{4} \mathrm{P}_{2} \mathrm{O}_{7} \cdot 10 \mathrm{H}_{2} \mathrm{O}(\Pi \Phi \mathrm{H})$.

Для сравнения изучено влияние катионного ПАВ цетилтриметиламмоний бромида (ЦТАБ) и силиката натрия $\left(\mathrm{Na}_{2} \mathrm{SiO}_{3}\right)$ на тепловые характеристики при кипении $0.2 \%$-ных НЖ на основе углеродных нанотрубок (УНТ) и синтетического алмаза (СА) соответственно, полученных тем же УЗ методом (см. таблицу). УНТ получены методом каталитической конденсации газа в Институте газа НАН Украины, СА - продукт производства Полтавского завода искусственных алмазов и алмазного инструмента (Украина).

Дисперсионный анализ и определение электрокинетического Z-потенциала НЖ проводили на лазерном корреляционном спектрометре ZetaSizer NANO-ZS (Malvern Instrument, UK), а поверхностное натяжение определяли методом пластинки Вильгельми [22] (модифицированный тензиометр K6 (KRÜSS GmbH, Germany)). Bce наносуспензии имели полидисперсный характер распределения частиц по размерам (табл. 1). Во всех нанодисперсиях содержание твердой фазы было значительно ниже точки перколяции, соответствующей резкому увеличению вязкости [23].

Кривые кипения дистиллированной воды и испытуемых НЖ записывали при постоянной скорости подъема удельной тепловой нагрузки $\left(1.1 \mathrm{~kW} / \mathrm{m}^{2} \mathrm{~s}\right)$ на специально разработанном и полностью автоматизированном стенде [24,25]. Стенд работает как на переменном, так и на постоянном токе и управляется специально созданной компьютерной программой. Аналого-цифровой преобразователь и сигнальные нормализаторы также входили в измерительную систему в дополнение к ПК. Нормализаторы обеспечивали как преобразование измеряемых сигналов в нормализованные сигналы, которые поступали в аналого-цифровом преобразователе, так и фильтрацию, а также линеаризацию входных сигналов от датчиков тока и температуры.

Величина УТП $(q)$, как обычно, рассчитывалась, как $q=I U /(\pi D L)$, где $I-$ сила тока $(\mathrm{A}), U-$ напряжение $(\mathrm{V}), \pi D L-$ площадь внешней поверхно- сти нагревателя (нихромовой проволоки), $\mathrm{m}^{2}$. Соответственно коэффициент теплоотдачи $\alpha=q /\left(t_{w}-t_{f}\right)$, где $\left(t_{w}-t_{f}\right)$ - разница между температурами стенки и кипящего флюида.

Температуру наружной поверхности нагревателя $t_{w}$ определяли по зависимости электрического сопротивления нихромовой проволоки от температуры [24]. Все измерения электрических и расчетных тепловых параметров (ток, напряжение, температура, УТП, КТО и др.) были выполнены с использованием разработанного программного обеспечения. Компьютером одновременно строились графические зависимости между указанными параметрами в режиме онлайн. Погрешность измерения УТП и КТО не превышала 3\%.

Устойчивость исследуемых нанодисперсий была оценена как по кинетике седиментации, так и по величинам их $\zeta$-потенциала (см. таблицу). Введение всего 0.05 mass.\% диспергента в алюмосиликатную дисперсию резко увеличивает $\xi$-потенциал и высоту электростатического барьера отталкивания между частицами с 5-7 до 45-55kT, смещая равновесие агрегация $\leftrightarrows$ дезагрегация вправо и обеспечивая высокую стабильность нанофлюида (см. AlSi-7 + 0.05\% ПФН, таблица). Опыты показали очень медленную диффузную седиментацию таких дисперсий с образованием плотного осадка.

\section{2. Результаты и их обсуждение}

\section{1. Влияние добавок неорганического диспергента на тепловые параметры при кипении алюмосиликатных НЖ}

Влияние этого фактора при кипении в свободном объеме алюмосиликатных НЖ в установке с проволочным Ni/Cr-нагревателем, питаемым переменным током, было детально рассмотрено нами ранее $[9,10]$. Было установлено, что незначительные добавки диспергента (пирофосфата натрия) к алюмосиликатным НЖ изменяют структуру отложенного на нагревателе осадка, приводя к двукратному росту КТП по сравнению с базовой жидкостью (водой). Мы пришли к выводу, что 

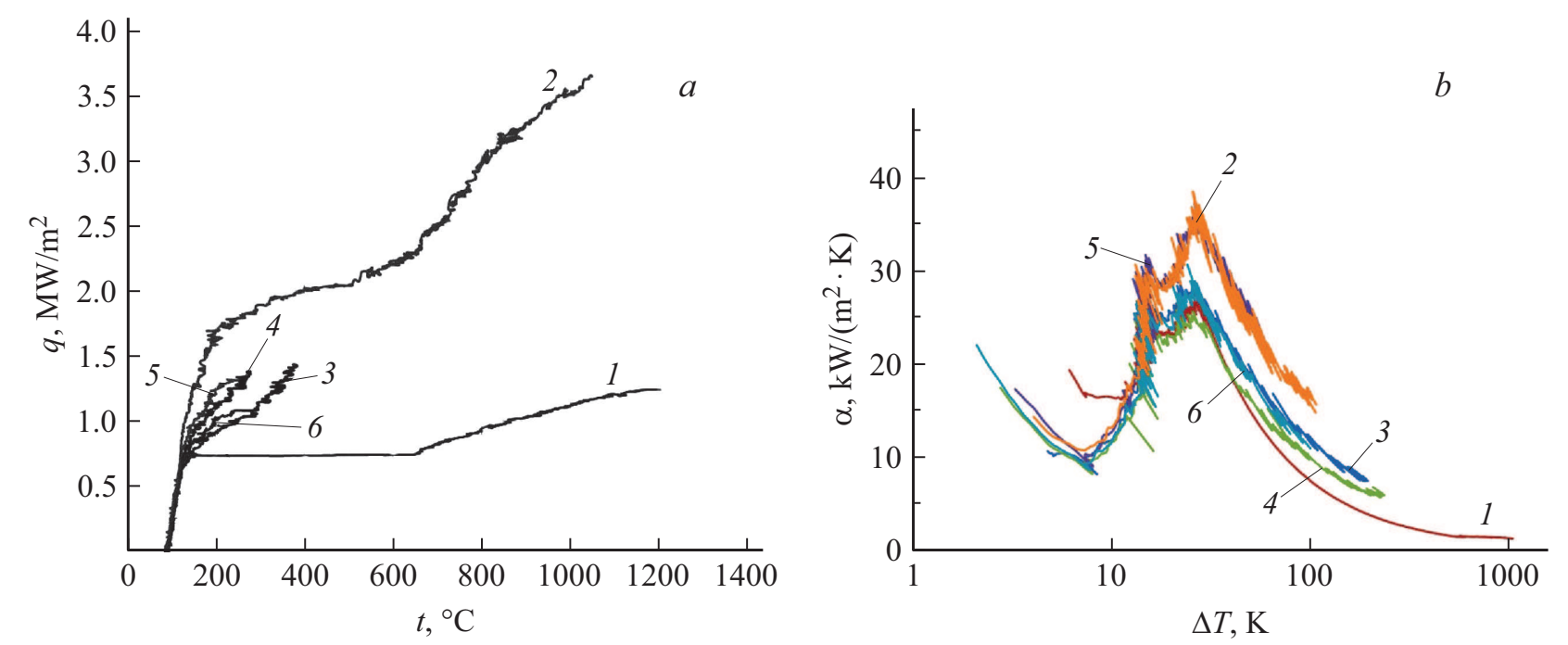

Рис. 1. Кривые кипения $(a)$ и зависимости коэффициента теплообмена от величины перегрева $\Delta T(b)$ при кипении ДВ $(1)$ и НЖ AlSi-7 с различными добавками пирофосфата натрия (кривые $2-6)$, mass.\%: $2-0,3-0.015,4-0.03,5-0.05,6-0.1$.
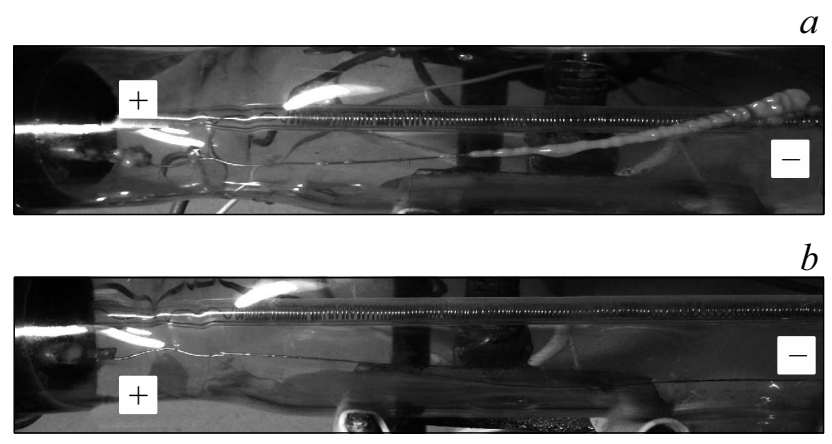

Рис. 2. Фотоизображения нагревателя питаемого постоянным током после кипения AlSi-7 и пережога в отсутствие $(a)$ и в присутствии $0.03 \%$ диспергента $(b)$.

рост КТП в этом случае был связан как с повышением степени дисперсности минерала и числа его частиц в единице объема вследствие распада его игольчатых пачек, так и с образованием тонкого и равномерного гелеобразного слоя из наночастиц алюмосиликата вокруг нагревателя $[9,10]$.

Однако, как показывает опыт, добавки диспергентов не всегда приводят к росту КТП и КТО. Это зависит не только от химической природы добавок и наночастиц [10], но и от рода электрического тока нагрева [11]. Ранее $[10,11]$ нами было обнаружено, что наложение на процесс кипения НЖ электрического поля постоянного тока может нарушить равномерность и „архитектуру“ отложений на поверхности нагревателя, тем самым влияя на тепловые параметры кипения НЖ.

В качестве примера на рис. 1 показано влияние добавок того же пирофосфата натрия на кривые кипения НЖ AlSi-7 и на зависимости КТО от величины перегрева $\Delta T$, полученные на установке, питаемой постоянным током. Кипение исходной НЖ без диспергента (кривая 2) ха- рактеризуется максимальными величинами КТП и КТО благодаря отложению на поверхности нагрева ажурного гелеобразного слоя наночастиц (рис. 2, a), вызывающего интенсификацию теплообмена и защищающего нагреватель от перегрева. Максимум УТП пережога в этом случае достигает величины $3.7 \mathrm{MW} / \mathrm{m}^{2}$, что на $500 \%$ превышает КТП для воды. Редкой особенностью кривой кипения исходной НЖ-7 является отсутствие „классического“ кризиса кипения. Это выражается в дальнейшем росте УТП после начала падения КТО, а также в том, что „кризисное явление“ при кипении данной НЖ отодвигается к более высоким тепловым нагрузкам и теряет свою внезапность. Такое поведение исключительно важно для своевременного предотвращения развития аварийных ситуаций на производствах.

Введение и последующее увеличение концентрации диспергента в НЖ (рис. 1, $a$, кривые 3-6) приводят к резкому изменению формы кривых кипения и внезап-

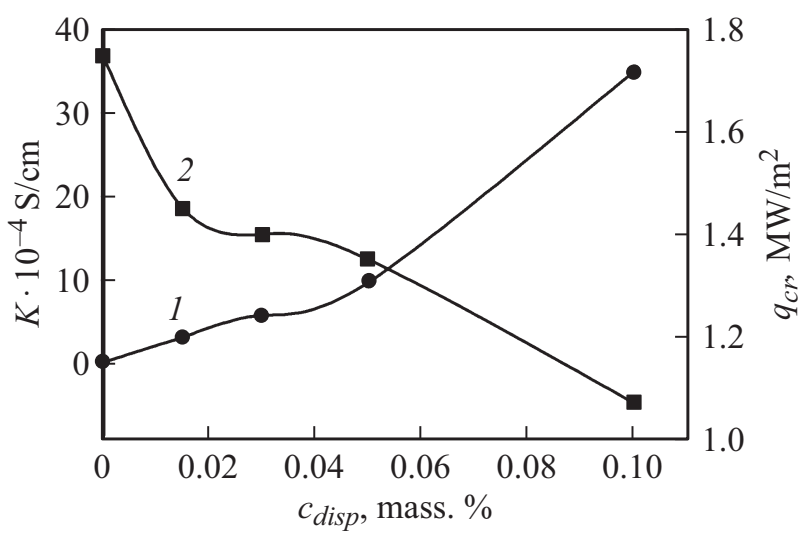

Рис. 3. Зависимости удельной электропроводности (1) и критического теплового потока при кипении $0.3 \%$-ной НЖ AlSi-7 (2) от концентрации добавок пирофосфата натрия. 
ному предкризисному пережогу нагревателя, а также к уменьшению тепловых параметров кипения НЖ. Все это вызвано сильной электростатической стабилизацией дисперсии $(\xi \approx-50-60 \mathrm{mV})$ и, как следствие, возникновением высокого барьера отталкивания между наночастицами и поверхностью нагрева из-за их заряжения одноименным зарядом. Причина наблюдаемого явления заключается в одновременной избирательной адсорбции четырехзарядных фосфат-анионов $\left[\mathrm{P}_{2} \mathrm{O}_{7}\right]^{4-}$ на поверхности нагрева и на частицах глинистых кристаллов с последующим увеличением плотности их суммарного отрицательного заряда [26]. Вследствие этого отложение наночастиц при кипении и образование пористого слоя на поверхности теплообмена практически не наблюдаются (рис. 2, b). Из-за отсутствия такого слоя теплоотдача остается низкой, вследствие чего при дальнейшем подъеме тепловой нагрузки, превышающей КТП воды, происходит внезапный перегрев и пережог нагревателя (рис. 1, $a$, кривые 3-6).

На рис. 3 сопоставлены зависимости критического теплового потока при кипении и удельной электропроводности НЖ AlSi-7 от концентрации $\mathrm{Na}_{4} \mathrm{P}_{2} \mathrm{O}_{7}$. Обращает на себя внимание антибатное изменение величины КТП по сравнению с изменением электропроводности НЖ по мере увеличения концентрации щелочного реагента. Как известно [26], рост рН из-за гидролиза пирофосфата натрия способствует диссоциации поверхност-

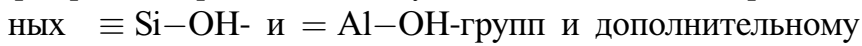
увеличению плотности отрицательного заряда частиц согласно схеме:

$$
\begin{gathered}
\equiv \mathrm{Si}-\mathrm{OH}+\mathrm{NaOH} \rightarrow \equiv \mathrm{Si}-\mathrm{O}^{-} \mathrm{Na}^{+}+\mathrm{H}_{2} \mathrm{O}, \\
=\mathrm{Al}(\mathrm{FeMg})-\mathrm{OH}+\mathrm{NaOH} \rightarrow=\mathrm{Al}-\mathrm{O}^{-} \mathrm{Na}^{+}+\mathrm{H}_{2} \mathrm{O},
\end{gathered}
$$

а рост электропроводности НЖ указывает на увеличение ионной силы и сжатие двойного электрического слоя НЧ. Следовательно, чрезмерный рост этих параметров приводит к ухудшению тепловых свойств кипящих НЖ.

Опыт показывает, что при чрезмерном содержании диспергента и нагреве постоянным током отложение НЧ на поверхности теплообмена вообще не происходит, а пузырьковый режим кипения внезапно сменяется пленочным, что при дальнейшем подъеме тепловой нагрузки завершается пережогом нагревателя.

Причина наблюдаемого явления двояка: с одной стороны, она связана с наличием высокого заряда на частицах и возникновением мощного электростатического барьера отталкивания между частицами и поверхностью теплообмена, препятствующего, особенно в случае применения постоянного тока, равномерному отложению на поверхности нагрева пористого слоя достаточной толщины и проницаемости, с другой стороны, если в НЖ диспергента мало, то незначительное отложение частиц на нагревателе все же может произойти, но такие отложения очень плотные и непористые. Это резко ухудшает циркуляцию жидкости и пара в зоне теплообмена, вызывая перегрев и пережог нагревателя при дальнейшем подъеме тепловой нагрузки.

Полученные данные еще раз подтверждают роль наноструктурных отложений на поверхности нагрева в интенсификации теплообмена при кипении [11]. Концепция о влиянии отложенного на поверхности теплообмена пористого слоя на коэффициент теплоотдачи была выдвинута относительно недавно в работах Buongiorno с сотр. [27,28] и получила подтверждение и дальнейшее развитие в работах корейской $[4,29,30]$, российской $[13,14]$ школ исследователей и в наших работах $[9-11,21,24]$.

Согласно этим исследованиям, влияние наноотложений, возникающих при пузырьковом кипении наножидкостей, на рост КТП и КТО объясняется способностью НЖ произвести следующие эффекты:

- резкое увеличение количества парообразующих центров на поверхности теплообмена в результате формирования пористого слоя с высокой шероховатостью;

- многократный рост площади поверхности теплообмена;

- повышение гидрофильности и смачиваемости поверхности нагрева (снижение контактного угла смачивания);

- дополнительное „всасывание“ жидкости в зону теплообмена за счет действия капиллярных сил в приповерхностном пористом слое [31,32].

Помимо перечисленных эффектов, весьма вероятно $[9,28]$, что отложенный пористый слой препятствует расширению и слиянию „горячих/сухих“ пятен на металлической поверхности, задерживая наступление КТП и кризиса кипения и защищая нагреватель от пережога.

\section{2. Влияние диспергентов органического и неорганического происхождения на тепловые параметры при кипении углеродсодержащих НЖ}

В разд. 2.2. будет показано, что, несмотря на общность механизма действия, характер влияния диспергентов и стабилизаторов на теплопередающие характеристики при кипении НЖ зависит от физико-химической природы наночастиц и добавок. При этом важно подчеркнуть, что, несмотря на то, что теплопроводность использованных нами УНТ (около $2000 \mathrm{~W} / \mathrm{m} \cdot \mathrm{K}$ ) и СА $(2300 \mathrm{~W} / \mathrm{m} \cdot \mathrm{K})$ на много порядков превышает теплопроводность глин $(0.9 \mathrm{~W} / \mathrm{m} \cdot \mathrm{K})$, тем не менее тепловые параметры при кипении соответствующих НЖ не столь сильно отличаются между собой. Это однозначно свидетельствует об определяющей роли конвекции в теплоотдаче при пузырьковом кипении.

На рис. 4 приведены кривые кипения и соответствующие зависимости КТО от величины перегрева $(\Delta T)$ для дистиллированной воды и НЖ на основе УНТ, стабилизированной катионным ПАВ-ЦТАБ. Несмотря на высокую теплопроводность наночастиц УНТ и на 

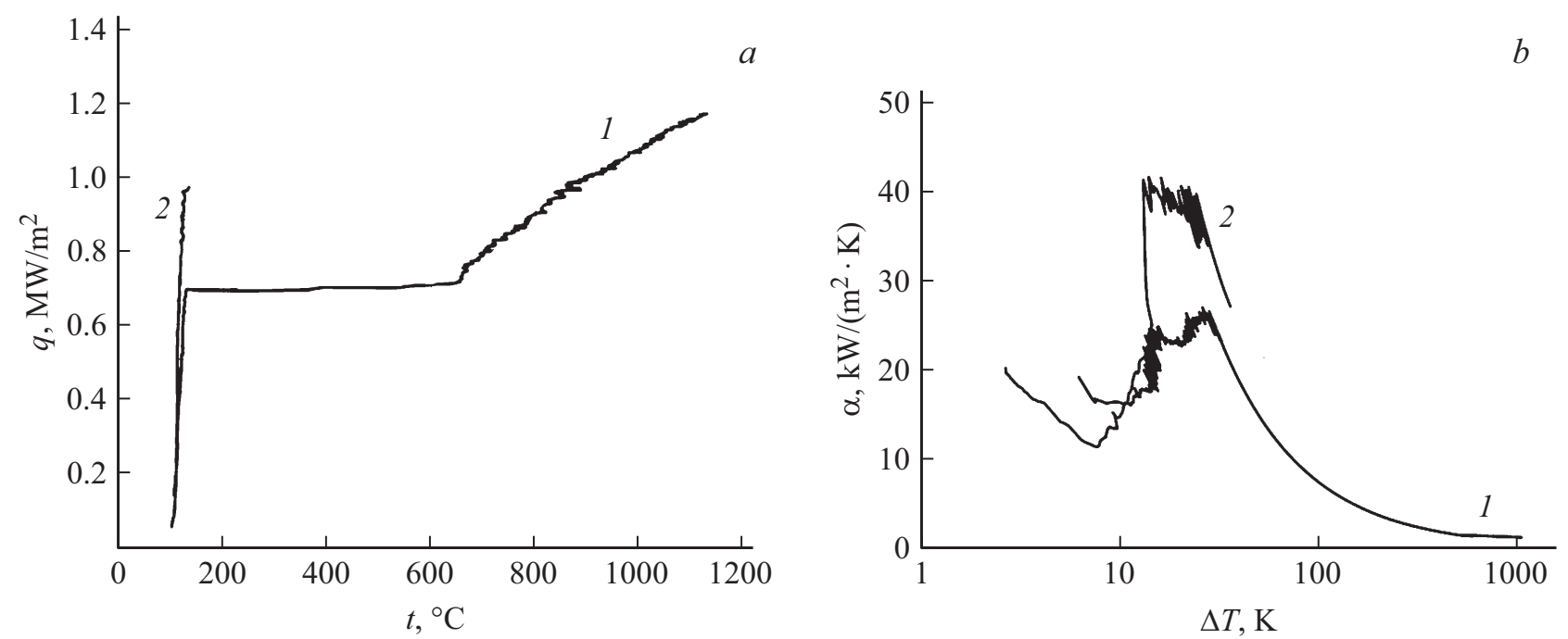

Рис. 4. $a-$ кривые кипения дистиллированной воды $(1)$ и НЖ-13 на основе УНТ стабилизированной ЦТАБ $(2)$; $b-$ соответствующие зависимости КТО от величины перегрева $\Delta T$.
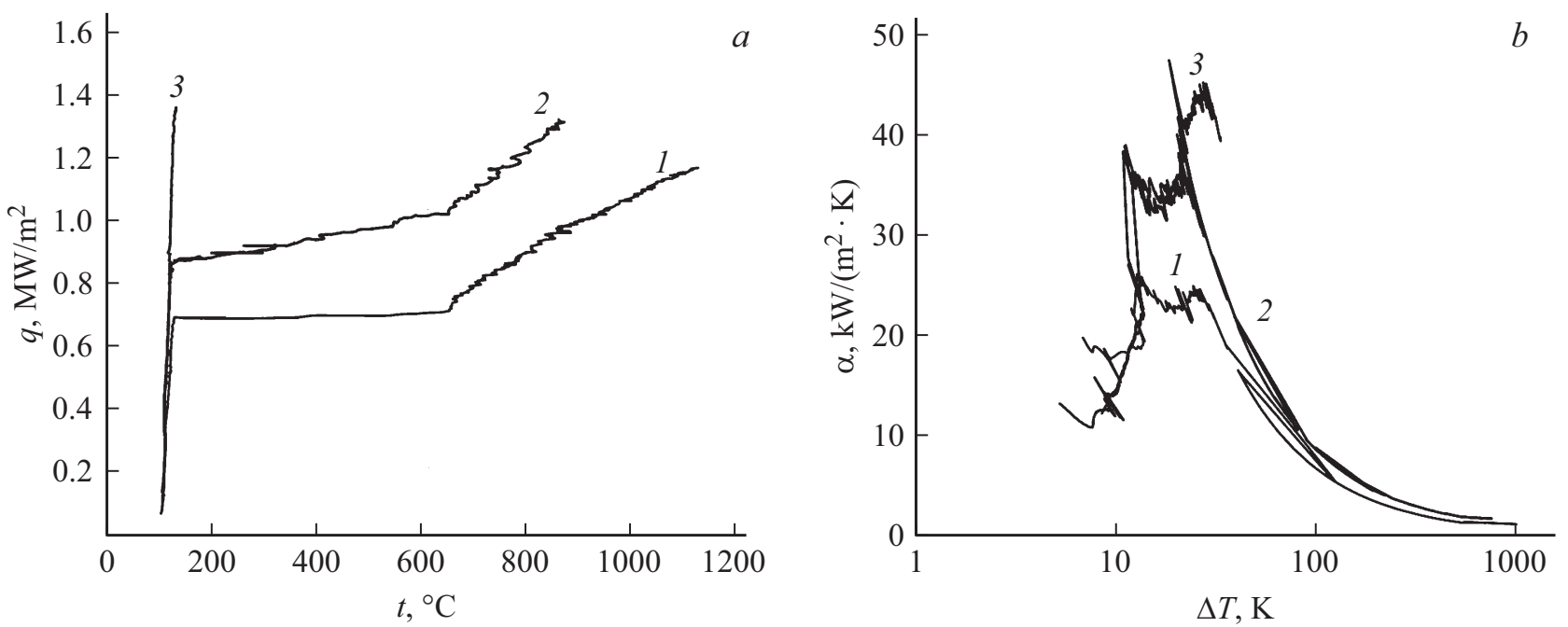

Рис. 5. $a$ - кривые кипения дистиллированной воды $(1)$, исходной водно-алмазной НЖ-24 (2) и водно-алмазной НЖ- 24 с $0.05 \%$ ной добавкой силиката натрия (3); $b$ - соответствующие зависимости КТО от величины перегрева $\Delta T$.

то, что седиментационная стабильность этой НЖ безупречна (измеряется годами), критический тепловой поток при кипении наступает внезапно, едва достигнув $0.95 \mathrm{MW} / \mathrm{m}^{2}$, и завершается пережогом нагревателя, не доходя до пленочного режима кипения. Такое тепловое поведение данной НЖ обусловлено добавкой стабилизатора ЦТАБ ${ }^{+}$, катионы которого сильно адсорбируются на частицах УНТ и на поверхности нагрева, сообщая им высокий одноименный положительный заряд. Возникающее при этом взаимное электростатическое отталкивание зарядов препятствует отложению на поверхности нагрева пористого слоя, что не способствует теплообмену и приводит к перегреву и пережогу нагревателя с ростом тепловой нагрузки. Не исключено, что небольшая величина УТП и резкое падение КТО связаны также и с высоким термическим сопротивлением адсорбционного слоя ПАВ.

Другая причина раннего пережога нагревателя может быть обусловлена резким снижением поверхностного натяжения НЖ (от 72 до $38 \mathrm{mN} / \mathrm{m} !)$ под действием ПАВ и обильным пенообразованием при кипении, вызывающим вытеснение нанофлюида паром из зоны теплообмена и резкое падение КТО (рис. 4,b). Как видно из рисунка, после достижения высокого начального значения КТО $\left(42000 \mathrm{~W} / \mathrm{m}^{2} \cdot \mathrm{K}\right)$ дальнейшее повышение тепловой нагрузки сопровождается обвалом КТО. Это свидетельствует об отрицательном влиянии стабилизатора на КТП и теплопередающую способность НЖ при кипении.

На рис. 5 приведен другой пример влияния неорганического диспергента - силиката натрия на кривые 
кипения и параметры теплопередачи при кипении НЖ на основе синтетического алмаза СА 1/0.

Как следует из анализа кривых кипения и зависимостей КТО от величины перегрева, небольшая добавка $\mathrm{Na}_{2} \mathrm{SiO}_{3}(0.05$ mass.\%), хотя вначале кипения и повышает КТП и КТО, однако при дальнейшем увеличении $\Delta T$ вызывает внезапный предкризисный пережог нагревателя (рис. 5, кривые 3). Причиной этого является одновременная адсорбция анионов $\mathrm{SiO}_{3}^{2-}$ на частицах алмаза и на поверхности нагрева со всеми вытекающими отсюда последствиями $(\xi=-54 \mathrm{mV})$. Так как при сверхтонком измельчении исходного нанопорошка алмаза уже были использованы диспергенты, их остаточные количества на частицах также сказались на форме кривой кипения соответствующей НЖ СА $1 / 0$ (кривая 2) в виде почти горизонтального участка кризиса кипения, как при кипении ДВ (кривая 1). Поскольку величина КТП $\left(0.87 \mathrm{MW} / \mathrm{m}^{2}\right)$ в этом случае незначительно превышала КТП ДВ, удалось наблюдать и участок пленочного кипения $\left(650-900^{\circ} \mathrm{C}\right)$. Высокие же значения КТО в этом случае, достигающие $45000 \mathrm{~W} / \mathrm{m}^{2} \cdot \mathrm{K}$ (рис. 5,b), объясняются очень низким термическим сопротивлением пористого слоя из-за огромной теплопроводности частиц алмаза $(k \sim 2300 \mathrm{~W} / \mathrm{m} \cdot \mathrm{K})$.

Таким образом, проблема стабилизации наножидкостей, предназначенных для интенсификации теплообмена при кипении, сопряжена с двумя взаимоисключающими эффектами: улучшением стабильности НЖ и одновременным ухудшением их тепловых характеристик. Использование ионных диспергентов, стабилизаторов и, особенно, пенящихся ПАВ, повышающих заряд частиц и улучшающих агрегативную устойчивость, в то же время отрицательно сказывается на теплоотдаче и стабильности наножидкостей к кипению, нередко приводя к нежелательному пенообразованию. Как уже отмечалось, такое влияние объясняется одновременной адсорбцией ионов стабилизатора или диспергента на наночастицах и на поверхности теплообмена с последующим возникновением отталкивания между ними. Все это препятствует отложению наночастиц на поверхности нагрева в процессе кипения и образованию шероховатого пористого слоя, который является мощным генератором образования пузырьков - усилителей конвекции. Причем, как показано в работе [30], шероховатость пористого слоя является доминирующей величиной, определяющей рост критического теплового потока при кипении НЖ.

Другой отрицательно влияющий на теплообмен фактор - это усиление взаимодействия заряженных частиц с электрическим полем нагревателя, питаемого постоянным током, по мере роста поверхностного заряда, вызванного адсорбцией ионов диспергента. Результатами такого взаимодействия являются электрокоагуляция НЖ и электрофорез $[11,33]$, вызывающие резко неравномерное отложение наночастиц на поверхности нагрева и приближающие кризис кипения [11,34].

Из вышеприведенных результатов логически вытекает целесообразность использования переменного тока для нагрева, а также добавок неионных диспергентов для обеспечения стабильности НЖ. Хотя и в этом случае адсорбция неионных ПАВ на частицах и на поверхности нагрева чревата возникновением стерического барьера отталкивания между ними. Однако этот барьер является не столь дальнодействующим, как электростатический, а кроме того, его неионная природа позволит избежать искажающего влияния электрического поля нагревателя на структуру отложений и тепловые параметры НЖ.

\section{3. Влияние диспергентов на кризисные явления при кипении НЖ. Причины преждевременного докризисного пережога нагревателя}

Как видно, изучение механизма влияния диспергентов на тепловые свойства НЖ проливает свет и на причины такого опасного явления, как внезапный докризисный пережог нагревателя. Однако авторы таких работ, не подозревая о влиянии диспергента (о наличии избыточного заряда на частицах и на поверхности теплообмена), приписывают этому явлению другие причины. На самом же деле, это часто наблюдаемое явление вызвано присутствием диспергента (стабилизатора) в НЖ, препятствующего отложению сплошного и достаточно оптимального по толщине и пористости слоя наночастиц на поверхности нагрева. Из-за низкой теплоотдачи почти оголенных (незащищенных) участков поверхности нагрева, незначительное превышение УТП над КТП воды $\left(0.7 \mathrm{MW} / \mathrm{m}^{2}\right)$ вызывает резкий локальный скачок температуры такого участка и мгновенное разрушение нагревателя. Как правило, в таких случаях не удается наблюдать режим пленочного кипения.

Пример такого явления описан в работе [35], в которой измерялась длина светящейся ленты с целью изучения возможных факторов, влияющих на теплопередачу в стабилизированных НЖ на основе кремнезема $\left(\mathrm{SiO}_{2}\right)$. Некоторое отложение частиц на проволоку обеспечивало высокую теплопередачу через межагломератные поры, что приводило к почти трехкратному увеличению теплового потока пережога при очень низких концентрациях. Но ранний предкризисный пережог и отсутствие режима пленочного кипения наблюдали во всех случаях не только из-за малой толщины слоя, но и из-за его высокой плотности упаковки частиц (отсутствия пор). На наш взгляд, это связано с тем, что при пузырьковом кипении высокостабилизированные наножидкости в отличие от слабоагрегированных дают очень плотные отложения.

Аналогичные кривые без режима пленочного кипения получены и в работе [13] на самых разных НЖ с наночастицами $\mathrm{SiO}_{2}, \mathrm{Al}_{2} \mathrm{O}_{3}, \mathrm{Fe}_{3} \mathrm{O}_{4}$ и алмаза. Несомненно, что наблюдать пленочное кипение для изученных НЖ авторы не смогли из-за наличия примесей диспергента. Нагреватель всегда выгорал до начала кризиса и перехода к пленочному режиму кипения. Кроме того, вероятно, это происходило также из-за высокой плотности отложений 

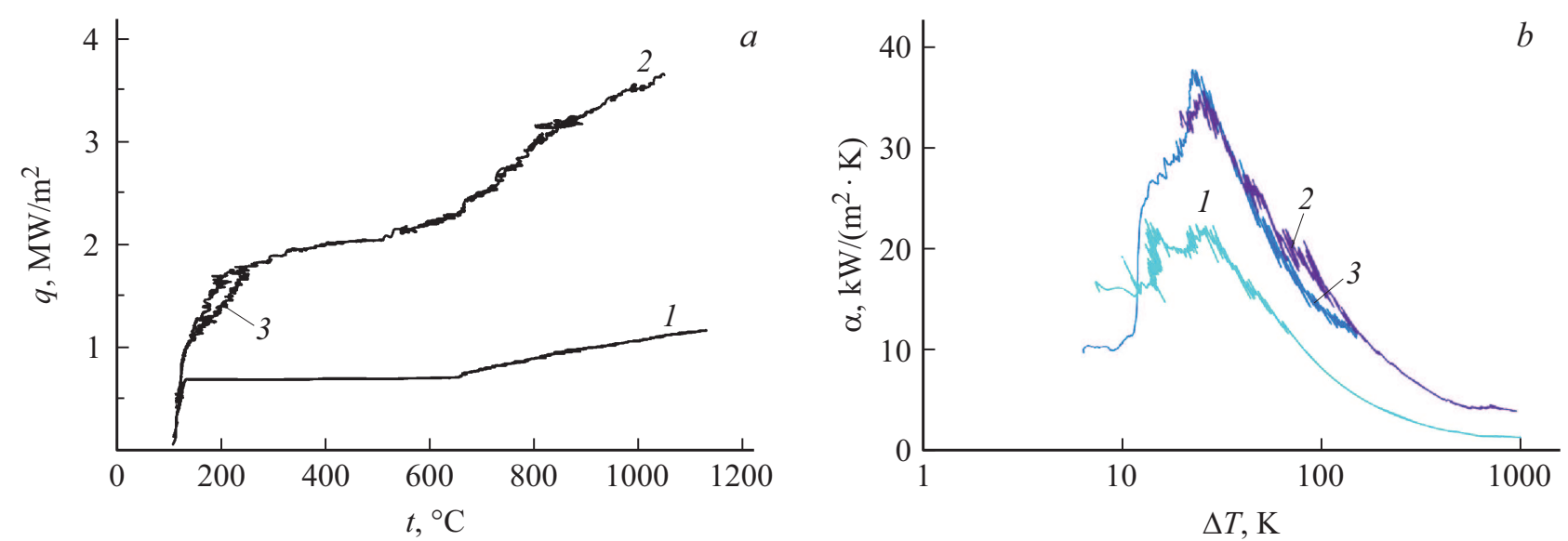

Рис. 6. $a$ - кривые кипения дистиллированной воды $(1)$ и исходной НЖ AlSi-7 с концентрацией твердой фазы $C_{\mathrm{H}}=0.65 \%(2)$ и разбавленной с $C_{\mathrm{H}}=0.3$ mass.\% (3); $b$ - соответствующие зависимости КТО от величины перегрева стенки $(\Delta T)$.
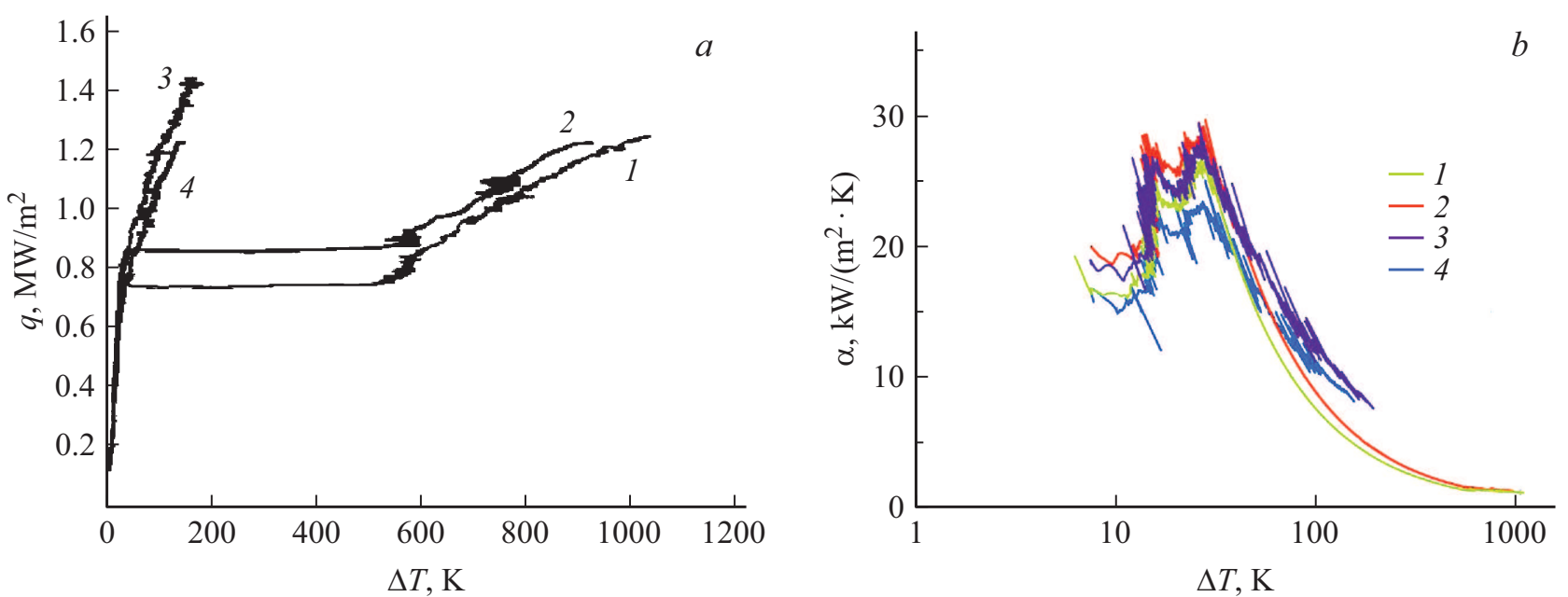

Рис. 7. $a$ - кривые кипения дистиллированной $(1,2)$ и водопроводной воды $(3,4) ; b$ - соответствующие зависимости КТО от величины перегрева $\Delta T$ в отсутствие $(1,3)$ и в присутствии $0.05 \%$ пирофосфата натрия $(2,4)$.

(отсутствия агрегации частиц и соответственно пор), что подтверждается зависимостью КТП в изученных ими НЖ от размера наночастиц [13]: КТП резко возрастал с увеличением размера наночастиц в пределах 10-100 nm. Это означает, что чем больше размер наночастиц в отложениях, тем больше пористость и шероховатость поверхности нагревателя, что усиливает кипение. Это предположение авторы подтвердили методом сканирующей электронной микроскопии.

Наши исследования показали, что, когда концентрация наночастиц в НЖ недостаточна для формирования при кипении сплошного пористого слоя оптимальной толщины, также наблюдается явление докризисного пережога нагревателя и более резкого падения КТО, хотя его максимум даже чуть выше, чем у более концентрированной НЖ (ср. кривые 2 и 3 на рис. 6). Поскольку в измерительной установке $\mathrm{Ni} / \mathrm{Cr}$-проволока служила одновременно нагревателем и интегральным термометром сопротивления, это делает невозможным определение температуры поверхности в отдельной его точке. По этой причине „точечная температура пережога“ на всех кривых кипения НЖ с добавками соответствует не реальной температуре плавления металла, а некой усредненной температуре проволоки $\left(200-400^{\circ} \mathrm{C}\right)$ (рис. $4, a$, $5, a, 6, a)$.

Еще один пример докризисного пережога нагревателя наблюдается при кипении водопроводной воды (BВ) (рис. 7). Но в данном случае причина раннего пережога нагревателя целиком связана с высокой плотностью слоя накипи, который образуется на молекулярном уровне (из-за разложения молекул гидрокарбонатов и отложения нерастворимых солей жесткости), а не на микро нано уровне, как при кипении НЖ. Этот случай типичен также и при длительной работе стиральных машин без добавок калгона, т. е. без диспергента (гексаметафосфата натрия) с тем отличием, что здесь процесс отложения накипи тормозится надолго присутствием моющих 


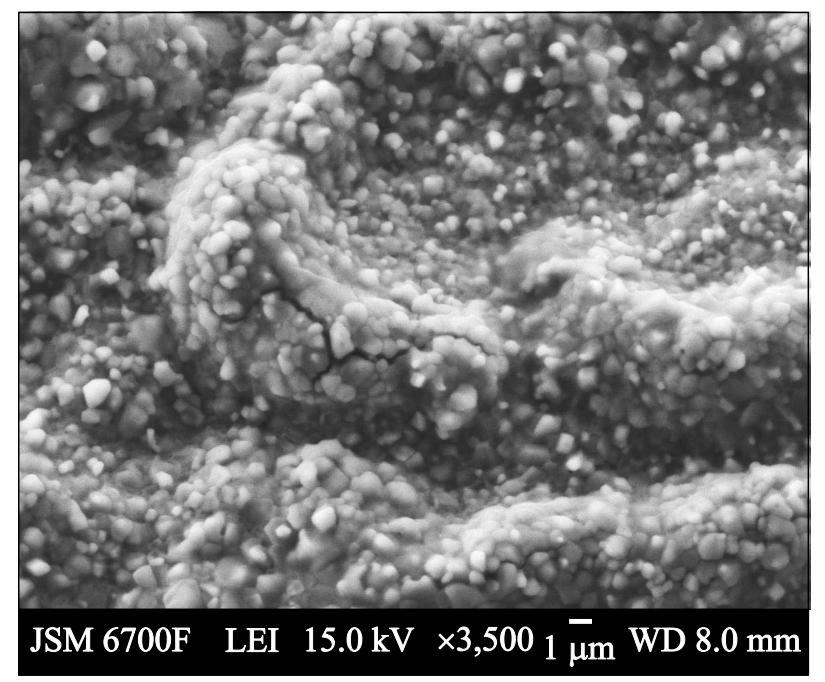

Рис. 8. SEM-фотография поверхности нагрева после кипения $0.05 \%$-ного раствора пирофосфата натрия в дистиллированной воде.

средств, а подаваемая тепловая нагрузка запрограммирована на уровне ниже КТП воды.

Рассмотрим более детально влияние диспергента (пирофосфата натрия) на кривые кипения дистиллированной и водопроводной воды (рис. 7). Для кривой кипения ДВ характерно появление горизонтального участка стремительного роста температуры нагревателя при достижении КТП, соответствующего наступлению кризиса кипения.

Кризис кипения дистиллированной воды (рис. 7, $a$, кривая 1) возникает из-за образования сплошной паровой пленки вокруг поверхности нагрева, которая изолирует ее от кипящей жидкости и приводит к резкому повышению температуры нагревателя и его разрушению в зависимости от температуры плавления применяемого металла. Добавка диспергента (кривая 2) слегка повышает КТП и КТО благодаря отложению тонкого сплошного слоя кристаллов пирофосфата на поверхности нагрева и зарождению дополнительных центров парообразования, но при повышении тепловой нагрузки выше КТП воды, такой плотный слой (рис. 8) не в состоянии защитить нагреватель от кризиса и пережога.

Кипение же обычной (водопроводной, бюветной) воды сопровождается вначале отложением на поверхности нагрева вокруг центров парообразования прерывистого слоя накипи, который постепенно уплотняется. Осадок образуется вследствие термического разложения молекул растворимых солей жесткости (гидрокарбонатов), имеющихся в большом количестве в обычных водах, и конденсации нерастворимых карбонатов на поверхности нагрева согласно схеме:

$$
M e\left(\mathrm{HCO}_{3}\right)_{2} \rightarrow M e \mathrm{CO}_{3} \downarrow+\mathrm{CO}_{2}+\mathrm{H}_{2} \mathrm{O},
$$

где $\mathrm{Me}$ - обычно ионы $\mathrm{Ca}^{2+}, \mathrm{Mg}^{2+}$.
Отложившиеся вначале кипения наночастицы нерастворимых карбонатов повышают шероховатость поверхности нагрева, создавая новые центры парообразования. Это временно усиливает пузырьковое кипение, обеспечивая более высокий КТП и КТО, чем у ДВ (рис. 7, $a$, кривая 3). Однако при дальнейшем кипении ВВ слой накипи резко уплотняется и термическое сопротивление нагревателя растет как в многослойной стенке, где коэффициент теплопроводности внешнего слоя $\lambda_{\mathrm{o} 1}$ гораздо меньше теплопроводности металлической стенки $\lambda_{\mathrm{mw}}$. Bсе это приводит к резкому скачку температуры и внезапному пережогу нагревателя даже при фиксированных значениях теплового потока, не превышающих КТП воды (что и происходит при работе стиральных машин без добавок калгона).

Добавка диспергента в этом случае (рис. 7, $a$, кривая 4) несколько понижает КТП и КТО из-за растворения части карбонатов, отложение которых на поверхности нагрева смогли бы создавать новые центры парообразования. Поскольку тепловая нагрузка при этом $\left(1.2 \mathrm{MW} / \mathrm{m}^{2}\right)$ значительно превышает КТП воды, это также приводит к внезапному предкризисному пережогу нагревателя (рис. 7, а, кривая 4).

Следовательно, при изучении механизма влияния диспергентов на КТП и теплоотдачу при кипении нанофлюидов, кроме стабилизирующего действия на взвешенные в объеме наночастицы, необходимо учесть их влияние в целом на микрорельеф и свойства поверхности нагревателя (заряд, шероховатость, пористость, плотность отложений, площадь поверхности теплообмена, смачиваемость).

Таким образом, в теплообменных процессах с кипением теплоносителя, где основную роль играют топологические и химические свойства поверхности нагрева, а основной вклад в теплопередачу вносит конвекция, добавки диспергентов, как правило, оказывают отрицательное влияние на КТП и КТО. Это происходит из-за того, что диспергент препятствует отложению достаточно толстого слоя НЧ на теплоотдающей поверхности, приводя к внезапному пережогу нагревателя до момента наступления кризиса кипения. Такое явление особенно ярко проявляется при нагреве $\mathrm{Ni} / \mathrm{Cr}$-проволоки постоянным током, электрическое поле которого резко искажает структуру отложений из-за наложения на процесс кипения НЖ явлений электрофореза и электрокоагуляции частиц $[11,34]$.

\section{Заключение}

При кипении НЖ с высоко теплопроводящими углеродными частицами (УНТ, алмаз) добавки диспергентов хотя и понижают КТП пережога поверхности нагрева, но вызывают кратковременный рост КТО, что объясняется дополнительным вкладом теплопроводности в увеличении теплоотдачи. Напротив, для алюмосиликатных и других НЖ с низкой теплопроводностью, при кипении 
которых теплопередача осуществляется преимущественно за счет конвекции и зависит главным образом от топологических и химических свойств поверхности нагрева, добавки диспергентов, как правило, ухудшают тепловые параметры НЖ как теплоносителей. Это связано с тем, что диспергенты препятствуют отложению НЧ и формированию пористого слоя на поверхности теплообмена.

\section{Финансирование работы}

Работа выполнена при финансовой поддержке бюджетной программы „Поддержка развития приоритетных направлений научных исследований“ (КПКВК 6541230).

\section{Конфликт интересов}

Авторы заявляют, что у них нет конфликта интересов.

\section{Список литературы}

[1] Das S.K., Choi S.U.S., Yu W., Pradeep T. Nanofluids: Science and Technology. Wiley-Interscience, New Jersey, 2007. 397 p.

[2] Yu W., France D.M., Routbort J.L., Choi S.U.S. // Heat Transfer Engineering. 2008. Vol. 29. N 5. P. 432-460.

[3] Das S.K., Putra N., Roetzel W. // Intern. J. Heat and Mass Transfer. 2003. Vol. 46. P. 851-862.

[4] Hyung Dae Kim // Nanoscale Res. Lett. 2011. Vol. 6. N 1. P. 415-433.

[5] Zhu D., Li X., Wang N., Wang X., Gao J., Li H. // Current Appl. Phys. 2009. Vol. 9. N 1. P. 131-139.

[6] Amrollahi A., Rashidi A.M., Emami Meibodi M., Kashefi K. // J. Experiment. Nanosci. 2009. Vol. 4. N 4. P. 347-363.

[7] Assael M.J., Metaxa I.N., Arvanitidis J., Christofilos D., Lioutas C. // Intern. J. Thermophys. 2005. Vol. 26. N 3. P. 647-664.

[8] Lingli Song, Renyuan Zhang, Lingbo Mao, Wenjie Zhu, Miaoyan Zheng // Appl. Mechanic. Mater. Online. 2011. Vol. 71-78. P. 122-125. ISSN: 1662-7482.

DOI: 10.4028/www.scientific.net/AMM.71-78.122

[9] Бондаренко Б.И., Морару В.Н., Сидоренко С.В., Комыш Д.В., Ховавко А.И. // Письма в ЖТФ. 2012. T. 38. Вып. 18. С. 68-78. [Bondarenko B.I., Moraru V.N., Sidorenko S.V., Komysh D.V., Khovavko A.I. // Tech. Phys. Lett. 2012. Vol. 38. N 9. P. 853-857.]

[10] Bondarenko B.I., Moraru V.N., Sydorenko S.V., Komysh D.V., Khovavko A.I., Snigur A.V. // Proceedings of the $8^{\text {th }}$ International Symposium on Heat Transfer ISHT-8 October 21-24, 2012, Beijing, China, ISHT8-04-05. P. 181-190.

[11] Bondarenko B.I., Moraru V.N., Sydorenko S.V., Komysh D.V., Khovavko A.I. // Nanosci. Nanoengineer. 2016. Vol. 4. N 1. P. 12-22.

[12] Eric Christopher Forrest. Nanoscale Modification of Key Surface Parameters to Augment Pool Boiling Heat Transfer and Critical Heat Flux in Water and Dielectric Fluids // Thesis for the degrees of bachelor of science and master of science in nuclear science and engineering at the Massachusetts Institute of Technology, 2009. $130 \mathrm{p}$.
[13] Minakov A.V., Pryazhnikov M.I., Guzei D.V., Zeer G.M., Rudyak V.Ya. // Intern. J. Thermal Sci. 2017. Vol. 116. P. 214-223.

[14] Суртаев А.С., Сердюков В.С., Павленко А.Н. // Российские нанотехнологии. Обзоры. 2016. Т. 11. № 11-12. C. 18-32. www.nanorf.ru

[15] Liang G., Mudawar I. // Int. J. Heat Mass Transf. 2018. Vol. 124. P. 423-453.

[16] Milanova D., Kumar R. // Appl. Phys. Lett. 2005. Vol. 87. P. 233107-1-3.

[17] Milanova D., Kumar R. // J. Heat Transfer. 2008. Vol. 130. P. 042401.

[18] Kumar R., Milanova D. // Appl. Phys. Lett. 2009. Vol. 94. P. 073107.

[19] Kathiravan R., Kumar R., Gupta A., Chandra R. // Intern. J. Heat. Mass Transfer. 2010. Vol. 53. P. 1673-1681.

[20] Тарасевич Ю.И. Строение и химия поверхности слоистых силикатов. Киев: Наукова думка, 1988. 248 с.

[21] Moraru V.N. // Clay Minerals. 2018. Vol. 53. N 2. P. 255-269.

[22] Адамсон А. Физическая химия поверхностей. М.: Мир, 1979. $568 \mathrm{c}$.

[23] Moraru V.N., Lebovka N.I., Chevchenko D.G. // Colloid. Surf. A.: Physicochem. Eng. Aspects. 2004. Vol. 242. P. 181-187.

[24] Bondarenko B.I., Moraru V.N., Ilyenko B.K., Khovavko A.I., Komysh D.V., Panov E.M., Sydorenko S.V., Snigur O.V. // Intern. J. Energ. Clean Environment. 2013. Vol. 14. N 2-3. P. 151-168.

[25] Bondarenko B.I., Moraru V.N., Sydorenko S.V., Komysh D.G. // Book of Abstracts 2-nd Conf. on AMN-APLOC, 5-7 January 2011, Singapore. P. 74.

[26] Van Olphen H. An Introduction to Clay Colloid Chemistry. NY:: John Wiley \& Sons, 1977. 318 p.

[27] Kim S.J., Bang I.C., Buongiorno J., Hu L.W. // Appl. Phys. Lett. 2006. Vol. 89. N 15. P. 153107. http://dx.doi.org/10.1063/1.2360892

[28] Kim S.J., Bang I.C., Buongiorno J., Hu L.W. // Bulletin of the Polish Academy of Sci. Tech. Sci. 2007. Vol. 55. N 2. P. 211-216.

[29] You S.M., Kim J.H., Kim K.H. // Appl. Phys. Lett. 2003. Vol. 83. P. 3374-3376. http://dx.doi.org/10.1063/1.1619206

[30] Pham Q.T., Kim T.I., Lee S.S., Chang S.H. // Appl. Thermal Engineer. 2012. Vol. 35. P. 157-165.

[31] Kim H.D., Kim M.H. // Appl. Phys. Lett. 2007. Vol. 91. P. 014104.

[32] Son H.H., Kim S.J. // Intern. J. Heat Mass Transfer. 2019. Vol. 138. P. 985-1001.

[33] Dukhin S.S., Estrela-Liopys V.R., Jolkhovsky E.K Electrosurface phenomena and electrofiltration. Kiev: Naukova dumka, 1985. 288 p. (in Russian).

[34] Бондаренко Б.И., Морару В.Н., Сидоренко С.В., Комыш Д.В., Гудков Н.Н. // Письма в ЖТФ. 2018. Т. 44. Вып. 11. С. 11-20. [Bondarenko B.I., Moraru V.N., Sidorenko S.V., Komysh D.V., Gudkov N.N. // Tech. Phys. Lett. 2018. Vol. 44. N 6. P. 461-464.]

[35] Marie Vazquez Diane. Experimental studies of the heat transfer characteristics of silica nanoparticle water-based dispersion in pool boiling using nichrome flat ribbons and wires. A thesis for the degree of Master of Science in Mechanical Engineering, Department of Mechanical, Materials, and Aerospace Engineering in the College of Engineering and Computer Science, B.S.M.E. University of Central Florida, Orlando, Florida, 2008. Spring Term 2010. 